Article

\title{
Corrosion Behavior of Keyhole-Free Friction Stir Spot Welded Joints of Dissimilar 6082 Aluminum Alloy and DP600 Galvanized Steel in 3.5\% $\mathrm{NaCl}$ Solution
}

\author{
Zhong-Ke Zhang ${ }^{1, *}$, Yang Yu ${ }^{1}{ }^{\mathbb{D}}$, Jian-Fei Zhang ${ }^{1}$ and Xi-Jing Wang ${ }^{1,2}$ \\ 1 School of Materials Science and Engineering, Lanzhou University of Technology, Lanzhou 730050, China; \\ yuyangmr@163.com (Y.Y.); 15155769500@163.com (J.-F.Z.); wangxj@lut.cn (X.-J.W.) \\ 2 State Key Laboratory of Advanced Processing and Recycling of Non-ferrous Metals, \\ Lanzhou University of Technology, Lanzhou 730050, China \\ * Correspondence: zhangzke@lut.cn; Tel.: +86-0931-297-3892
}

Received: 23 July 2017; Accepted: 27 August 2017; Published: 1 September 2017

\begin{abstract}
The corrosion behavior of keyhole-free friction stir spot welded joints of dissimilar 6082 aluminum alloy and DP600 galvanized steel in 3.5\% NaCl solution has been investigated by the immersion test and electrochemical analysis. The surface of the aluminum alloy produced exfoliation and pitting corrosion. The pitting occurred seriously on the interface of the 6082 aluminum alloy, but the steel had no corrosion. The corrosion galvanic couples were formed between elements of $\mathrm{Si}$ and $\mathrm{Fe}$ with a high electrode potential, and $\mathrm{Mg}$ and $\mathrm{Al}$ with a low electrode potential, around them. $\mathrm{Mg}$ and $\mathrm{Al}$ elements of $\mathrm{Mg}_{2} \mathrm{Si}$ and Si-containing solid-solution phase $\alpha(\mathrm{Al})$ preferentially became an anodic dissolution and formed exfoliation corrosion around the $\mathrm{Si}$ elements. Fe-rich phase $\theta\left(\mathrm{Al}_{3} \mathrm{Fe}\right)$ as the cathode caused corrosion of $\mathrm{Mg}$ and formed pitting around $\mathrm{Mg}$-rich phase $\beta\left(\mathrm{Al}_{3} \mathrm{Mg}_{2}\right)$ as the anode. The sequence of the corrosion resistance of different areas of the joints (with decreasing corrosion resistance) was WNZ (Weld Nugget Zone) > TMAZ (Thermo-mechanically Affected Zone) > BM (Base Metal) > HAZ (Heat-affected Zone). The joints of keyhole-free FSSW (Fiction Stir Spot Welding) of dissimilar 6082 aluminum alloy and DP600 galvanized steel have better corrosion resistance than base metal in $3.5 \% \mathrm{NaCl}$ solution.
\end{abstract}

Keywords: dissimilar aluminum/steel; keyhole-free FSSW; pitting; exfoliation corrosion; intermetallic compounds

\section{Introduction}

FSW (Friction stir welding) is a solid-state welding process invented by TWI (The Welding Institute) in 1991 that is mainly used with aluminum alloys. Compared with the traditional welding method, this technology produces a high joint quality, small welding distortion, small residual stress, green welding process and no pollution, and is widely used in aerospace, shipping, transportation and other fields [1-5].

For many years, the integrated structure of dissimilar aluminum/steel has seen it become the preferred technical development route of lightweight mechanical products, and the welding of dissimilar aluminum/steel has been an active but difficult part in the welding field. The welding methods used with dissimilar aluminum/steel are mostly solid-phase welding (such as friction welding, welding-brazing, etc.). However, the low efficiency and limits of size and shape of the workpiece mean these methods have difficulty in meeting the requirements of mass production, and this has restricted the application of the integrated structure of dissimilar aluminum/steel [6-8]. Meanwhile, there are some problems in the traditional welding of dissimilar aluminum/steel, including the different melting points of aluminum and steel, slag of joints formed by aluminum oxide film and so on. 
However, FSW solves the issues discussed above in the welding process of dissimilar aluminum/steel. FSSW (Friction stir spot welding), as a new welding method of FSW, is used to realize the welding of dissimilar aluminum/steel in the automotive industry. The effect of friction between the shoulder of the welding tool and the workpiece can remove stubborn oxide film on the surface of the aluminum alloy. At the same time, dissimilar aluminum/steel is easy to connect when it reaches the thermoplastic state. Keyhole-free FSSW can eliminate the keyhole of the traditional FSSW by the backfill technology. Welded joints with good performance have been obtained by this method [9-14].

The corrosion problem of welded joints is very important, because the corrosion of the welded joint will directly affect its strength and fatigue life, etc. In the welded joints of dissimilar metals, the corrosion of the welded joints occurs more readily. At present, research reports on the corrosion of friction stir welded joints both domestic and abroad mainly focus on the joints of aluminum alloy. The corrosion of FSW joints of aluminum alloy is mainly pitting, exfoliation corrosion and intergranular corrosion [15-18]. Srinivasan et al. [19] studied the corrosion properties of FSW joints of AA2219-T87 in $3.5 \% \mathrm{NaCl}$ and $\mathrm{NaCl}+\mathrm{H}_{2} \mathrm{O}_{2}$ solutions. They found that the strengthening phase was dissolved and coarsened in the process of FSW, and the corrosion performance of the joint was better than that of the parent metal. This was consistent with the experimental results of Paglia et al. [20]. Emilie et al. [21] immersed the FSW joints of 2024-T3 aluminum alloy in the intergranular corrosion solution for $6 \mathrm{~h}$, and found that intergranular corrosion was most severe on HAZ (Heat-affected Zone); pitting and intergranular corrosion occurred on the base metal and TMAZ (Thermo-mechanically Affected Zone); and WNZ (Weld Nugget Zone) produced mainly pitting. However, some reports have come to the opposite conclusion. Fonda et al. [22] found that the corrosion of FSW joints of 5456 aluminum alloy occurred on WNZ, especially on the advancing side.

The corrosion of FSW joints of aluminum alloy is mainly related to the structure-sensitive properties and the second phase of FSW joints. The weld zone produces severe plastic deformation and recrystallization under the action of the pin and shoulder of the welding tool. The reduction of the grain size and the increase of the grain number per unit area lead to an increase in the inhomogeneity of the grain and grain boundary in electrochemical performance, which leads to deterioration of corrosion resistance. On the contrary, the strengthening phase is broken, partly dissolved and dispersed evenly in the grain. The refinement, homogenization and densification of the strengthening phase reduce the electrochemical inhomogeneity of grain boundaries and grains, which improves the corrosion resistance of joints [23-27]. At the same time, the second phases containing active elements and inactive elements forma corrosion galvanic couple. The second phases containing the inactive elements become the cathode, and the second phases containing the active element, as an anode, form anodic dissolution [26,28-31].

However, articles on the corrosion behavior of the welded joints of dissimilar aluminum/steel have been rarely reported, especially with keyhole-free FSSW joints. This paper studied the corrosion behavior of keyhole-free FSSW joints of dissimilar aluminum/steel in $3.5 \% \mathrm{NaCl}$ solution by the immersion test and electrochemical analysis. To this end, keyhole-free FSSW joints of dissimilar aluminum/steel were obtained by the rotary retractile keyhole-free FSSW machine. The influence factors and rules of corrosion behavior of dissimilar aluminum/steel keyhole-free FSSW joints were studied by the immersion test and electrochemical analysis in simulated seawater. The corrosion morphologies and corrosion products were observed by SEM (Scanning Electron Microscope) and XRD (X-ray Diffraction). The corrosion resistance and electrochemical corrosion mechanism were studied in this work.

\section{Materials and Methods}

6082 aluminum alloy plates and DP600galvanized steel plates were used in the experiment. Their dimensions were $150 \times 50 \times 2 \mathrm{~mm}^{3}$ and $150 \times 50 \times 1 \mathrm{~mm}^{3}$, respectively. Table 1 shows the chemical composition of 6082 aluminum alloy and DP600 galvanized steel. 
Table 1. The chemical composition of 6082 aluminum alloy and DP600 galvanized steel (in wt \%).

\begin{tabular}{cccccccccc}
\hline $\mathbf{6 0 8 2}$ & $\mathbf{S i}$ & $\mathbf{F e}$ & $\mathbf{C u}$ & $\mathbf{M n}$ & $\mathbf{M g}$ & $\mathbf{C r}$ & $\mathbf{Z n}$ & $\mathbf{T i}$ & Other \\
\hline Content & $0.7-1.3$ & 0.50 & 0.10 & $0.4-1.0$ & $0.6-1.2$ & 0.25 & 0.20 & 0.10 & 0.15 \\
DP600 & $\mathrm{C}$ & $\mathrm{Mn}$ & $\mathrm{Si}$ & $\mathrm{Al}$ & $\mathrm{Mo}$ & $\mathrm{Cr}$ & $\mathrm{Cu}$ & $\mathrm{S}$ & $\mathrm{P}$ \\
Content & 0.09 & 1.84 & 0.36 & 0.05 & 0.01 & 0.02 & 0.03 & 0.005 & 0.005 \\
\hline
\end{tabular}

The joints of dissimilar 6082 aluminum alloy and DP600 galvanized steel were welded by the rotary retractile keyhole-free FSSW machine. The welding tool was made of a nickel-based superalloy with a tool shoulder of $20 \mathrm{~mm}$ in diameter and a tool pin of $5 \mathrm{~mm}$ in diameter and $2.1 \mathrm{~mm}$ in length. The welding process is shown in Figure 1. In the welding process, the rotational speed and plunge speed of the welding tool were respectively $1000 \mathrm{rpm}$ and $5 \mathrm{~mm} / \mathrm{min}$ (as shown in Figure 1a). The tool plunge depth was $0.3 \mathrm{~mm}$ after the tool shoulder reached the surface of the workpiece (as shown in Figure 1b) $[32,33]$. Then, the welding tool was moved forward and the tool pin moved upward at a speed of $3 \mathrm{~mm} / \mathrm{min}$ and $5 \mathrm{~mm} / \mathrm{min}$, respectively (as shown in Figure 1c). This is equivalent to the tool pin moving forward about $1.5 \mathrm{~mm}$, in order to make the front of the plastic metal fill up the rear keyhole. At the same time, the workpiece table rotated slowly at a speed of $3 \mathrm{rpm}$ in the opposite direction of the welding tool until the tool pin was fully retracted, in order to obtain a large connection area and a better keyhole-free joint. Then, the workpiece table stopped rotating, and the welding tool moved upward (as shown in Figure 1d). When the welding tool was moved to a safe distance, the tool shoulder and tool pin simultaneously reset (as shown in Figure 1e). At this point, the keyhole-free FSSW joint was obtained (as shown in Figure 1f).

(a)

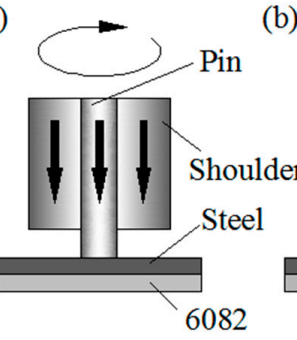

(d)

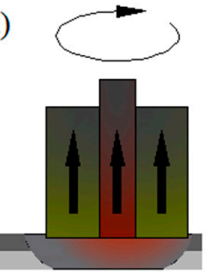

(b)
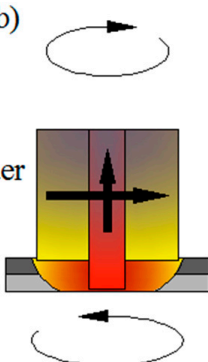

(e)

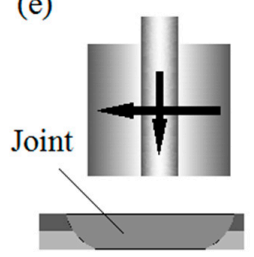

(c)

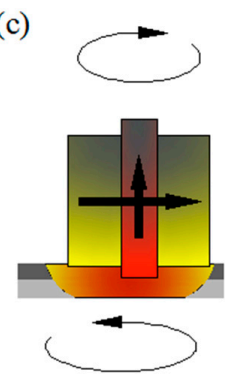

(f)

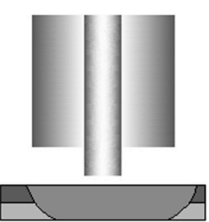

Figure 1. Welding process of the rotary retractile keyhole-free FSSW (Fiction Stir Spot Welding).

Figure 2 shows the sample and sketch map of the wire cutting of the keyhole-free friction stir spot welding joint of dissimilar 6082 aluminum alloy and DP600 galvanized steel. Specimens of the transverse section of the welded joints, with $40 \times 3 \times 15 \mathrm{~mm}^{3}$ dimensions, were cut off by wire cutting as shown in Figure $2 b$. The working surface of the transverse section included the WNZ (weld nugget zone), TMAZ (thermo-mechanically affected zone), HAZ (heat-affected zone) and BM (base metal) as shown in Figure $2 b$ in the four zones marked A, B, C and D. The transverse-section specimens were used for the immersion test and metallographic analysis. The specimens in the zones marked A, B, C and D were cut off for electrochemical experiments. Two B zones were glued together. One end of each specimen was connected with copper wires, the non-working surfaces were sealed with epoxy resin glue and the other ends were used as working surfaces whose areas of transverse section were $15 \mathrm{~mm}^{2}$. There were three specimens in each group of experiments. Transverse sections of all specimens were 
ground with sandpapers of 400\#, 600\#, 800\#, 1000\#, 1500\#, 2000\#, 3000\# and 5000\#, polished with polishing cloth, then cleaned with anhydrous alcohol.

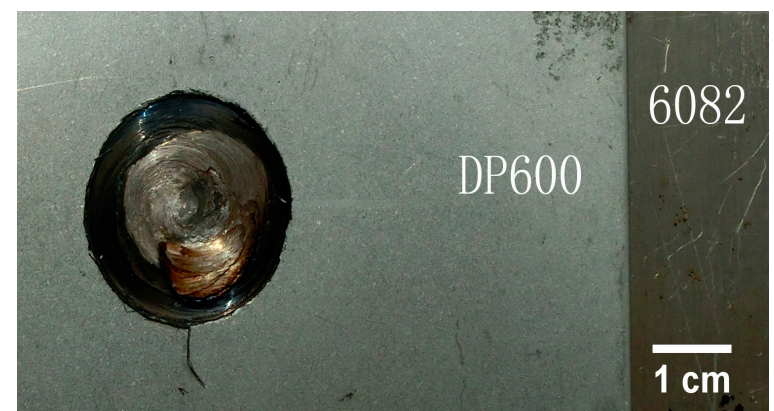

(a)

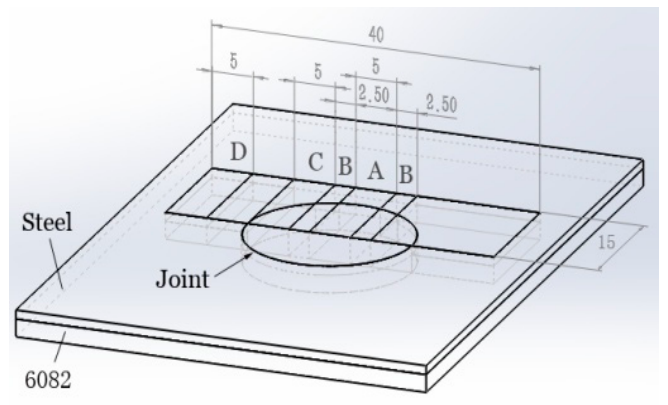

(b)

Figure 2. Keyhole-free FSSW joint of dissimilar 6082 aluminum alloy and DP600 galvanized steel: (a) the sample; (b) the sketch map of wire cutting.

The transverse-section specimens for the immersion test were suspended in 3.5\% $\mathrm{NaCl}$ solution for $48 \mathrm{~h}$ or $96 \mathrm{~h}$, then taken out for analysis of corrosion products by X-ray diffractometry (BRUKER-AXS Corporation, Billerica, MA, USA). Then, corrosion products were removed with rust liquid ( $50 \mathrm{~mL} \mathrm{H}_{3} \mathrm{PO}_{4}+20 \mathrm{~g} \mathrm{CrO}_{3}+1 \mathrm{~L}$ distilled water). The microscopic corrosion morphology of the WNZ, TMAZ, HAZ and BM was observed in order to draw a comparison of corrosion resistance of their welded joints by a JSM-5600LV low-vacuum scanning electron microscope of Japan Electron Optics Company (Tokyo, Japan), and the chemical composition of the pitting was measured to analyze corrosion factors by an X-ray energy-dispersive spectrometer (Oxford Instruments, Oxford, UK). The aluminum layer of the transverse section was corroded with Keller's etchant $\left(2.5 \mathrm{~mL} \mathrm{HNO}_{3}\right.$, $1.5 \mathrm{~mL} \mathrm{HCl}, 1.0 \mathrm{~mL} \mathrm{HF}$ and $95 \mathrm{~mL}$ distilled water) for $20 \mathrm{~s}$ and the steel layer was corroded with $4 \%$ nitric acid alcohol etchant for $4 \mathrm{~s}$. The metallographic structures of the welding joint were observed by an MeF3 Large Metallographic Microscope (Leica Corporation, Wetzlar, Germany).

Four specimens (WNZ, TMAZ, HAZ and BM) were subjected to the electrochemical test by the Electrochemical Workstation of Shanghai Chen Hua Instrument Co., Ltd. (Shanghai, China). The Pt electrode as the auxiliary electrode, and the saturated calomel electrode as the reference electrode, were used to measure the open circuit potential, impedance spectrum and polarization curve in $3.5 \%$ $\mathrm{NaCl}$ solution. The specimens were firstly immersed in the test solution for more than $30 \mathrm{~min}$ to ensure that the open circuit potential achieved stability for comparing the corrosion resistance of the welded joints. The frequency range of the AC impedance test was $10-100 \mathrm{kHz}$, and the amplitude of the AC excitation signal was $10 \mathrm{mV}$. The polarization curve was measured at a scanning speed of $1 \mathrm{mV} / \mathrm{s}$ and a scanning potential range of $-1.5 \mathrm{~V}$ to $1.5 \mathrm{~V}$.

\section{Results and Discussion}

\subsection{Corrosion Morphology and Mechanism}

Figure 3 shows the optical micrographs and the macroscopic corrosion morphology of the transverse section of keyhole-free FSSW joints before and after immersion in $3.5 \% \mathrm{NaCl}$ solution for $48 \mathrm{~h}$. The four A, B, C and D regions represent WNZ, TMAZ, HAZ and BM, respectively, in Figure 3a. The BM had a very weak rolling texture, as shown in Figure $3 a$, especially the aluminum alloy. The grains of HAZ significantly grew due to a large amount of heat input in FSSW, but the crystallographic orientation of the parent grains did not change significantly. The grains of TMAZ were elongated along the direction of rotation of the tool pin to form a texture. This was attributed to the continuous dynamic recrystallization induced by the substantial plastic deformation, and the significant amount of heat generated during FSW. Meanwhile, the initially large grains of WNZ were fragmented and refined 
and the fine-grained microstructures of dynamic recrystallization were formed on WNZ. This has been reported by Cho et al. [34] in the friction stir welded joint of high-strength pipe line steels. By contrasting Figure $3 a, b$, it can be seen that the surface of steel did not change after the immersion test, but corrosion holes and corrosion products appeared on the surface of 6082 aluminum alloy, which also lost its metallic luster. This illustrated that 6082 aluminum alloy of keyhole-free FSSW joints of dissimilar 6082 aluminum alloy and DP600 galvanized steel was prone to severe corrosion, while steel had almost no corrosion in $3.5 \% \mathrm{NaCl}$ solution.

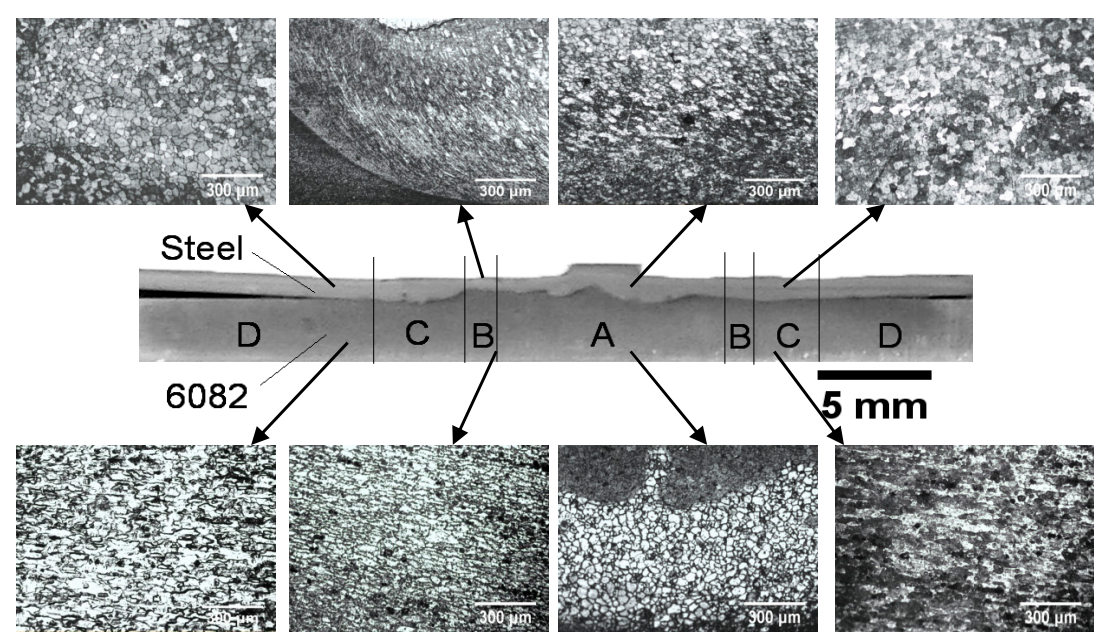

(a)

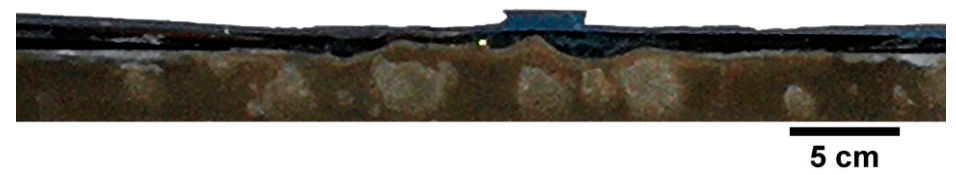

(b)

Figure 3. The optical micrographs and macroscopic corrosion morphology of the transverse section of keyhole-free FSSW joints. (a) The optical micrographs before immersion; (b) the macroscopic corrosion morphology after immersion in $3.5 \% \mathrm{NaCl}$ solution for $48 \mathrm{~h}$.

Figure 4 shows the microscopic corrosion morphology of the transverse section of keyhole-free FSSW joints after immersion for $48 \mathrm{~h}$. It can be seen in Figure 4 that the exfoliation corrosion firstly took place on the surface of 6082 aluminum alloy. The complete continuous fragments of aluminum alloy that were parallel to the metal surface were separated from the metal body near the surface of the interface. The surface away from the interface was producing transverse intergranular corrosion to form cracked fragments. Exfoliation corrosion follows the mechanism of stress corrosion cracking (SCC). That is, the wedge force of the corrosion product produces a tensile stress concentration at the crack tip, and the corrosion is extended by the SCC mechanism [35].Meanwhile, the surface of 6082 aluminum alloy formed the pitting corrosion on the exfoliation zone. This local corrosion was due to the local defects of the passive film on the surface of the metal and the passivation which was prevented. There was a difference in the potential between the defective area and the zone without defects. The defective area became the activated anode, and the surrounding area became the cathode region, which formed the occluded cell. As the anode area was very small and the current density was very large, the pitting nucleus was formed on the metal surface. Subsequently, the dissolved metal ions were hydrolyzed to form $\mathrm{H}^{+}$, and the $\mathrm{pH}$ of the local solution was lowered, which exacerbated the dissolution of the metal. The pitting was enlarged and deepened until the perforation [36]. There were many intermetallic compounds at the interface, but no signs of corrosion on the steel surface and interfacial layer. However, the surface of the aluminum alloy had a serious continuous corrosion hole at the junction of the aluminum alloy and interface. 


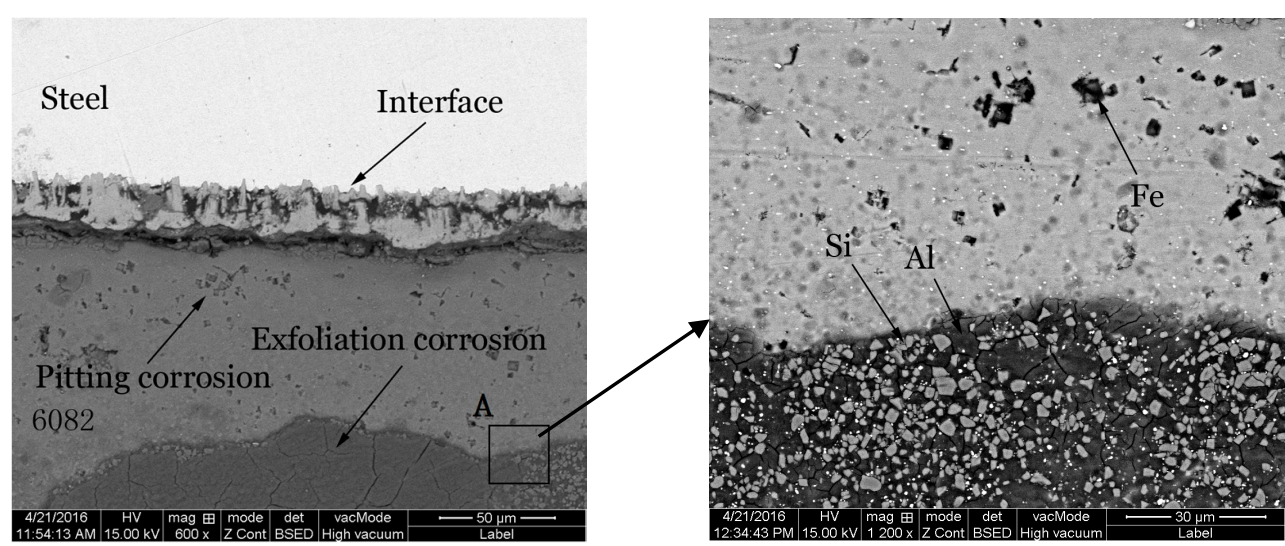

(a)

(b)

Figure 4. (a) The microscopic corrosion morphology of the transverse section of keyhole-free FSSW joints after immersion for $48 \mathrm{~h}$. (b) The elements at the interface and interfacial layer.

Figure 5 shows the microscopic corrosion morphology and the EDS (Energy Dispersion Spectrum) surface scan spectrum of the exfoliation corrosion zone. Figure 6 shows the microscopic corrosion morphology and the EDS line scan spectrum of the pitting zone. As shown in Figure 5, the white particles on the exfoliation corrosion zone were mainly comprised of elemental silicon and surrounded by elemental aluminum and magnesium. Figure 6 shows that the content of elemental aluminum and magnesium decreased in the pitting. However, the content of elemental Fe increased obviously at the edge of the pitting, as indicated by the elements in Figure 4.

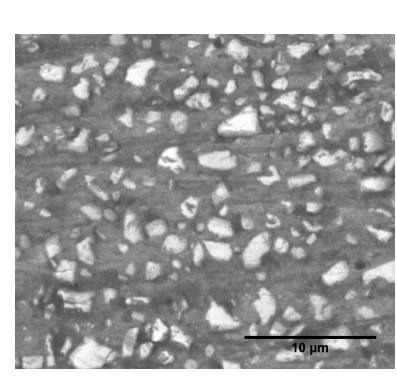

(a)

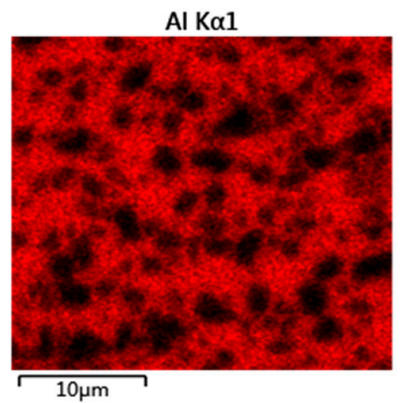

(b)

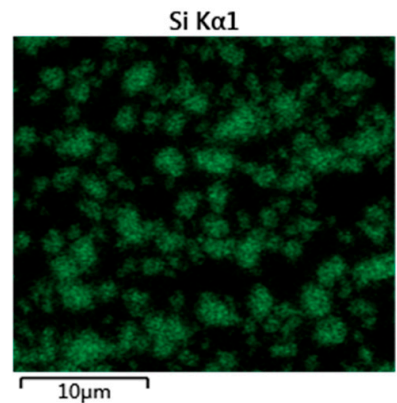

(c)

Figure 5. (a) The microscopic corrosion morphology and (b,c) EDS (Energy Dispersion Spectrum) surface scan spectrum of the exfoliation corrosion zone.

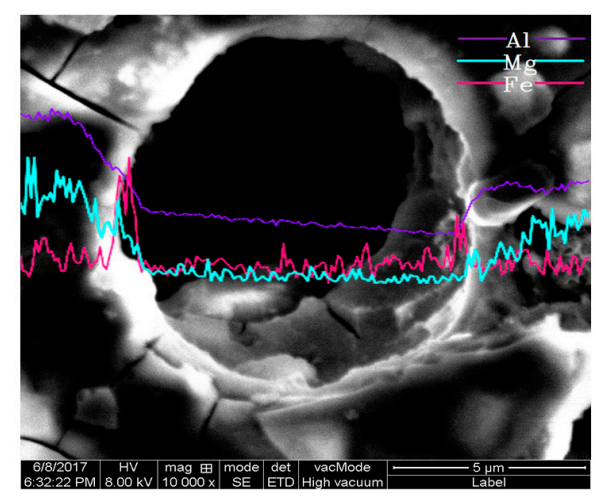

Figure 6. The microscopic corrosion morphology and EDS line scan spectrum of the pitting zone. 
Figure 7 shows the phase diagram of the Al-Fe binary alloy, drawn by Binary Alloy Phase Diagrams Software. It indicates that the keyhole-free FSSW joints of dissimilar 6082 aluminum alloy and DP600 galvanized steel may contain the intermetallic compounds $\mathrm{FeAl}, \mathrm{FeAl}_{2}$ and $\mathrm{FeAl}_{3}$.

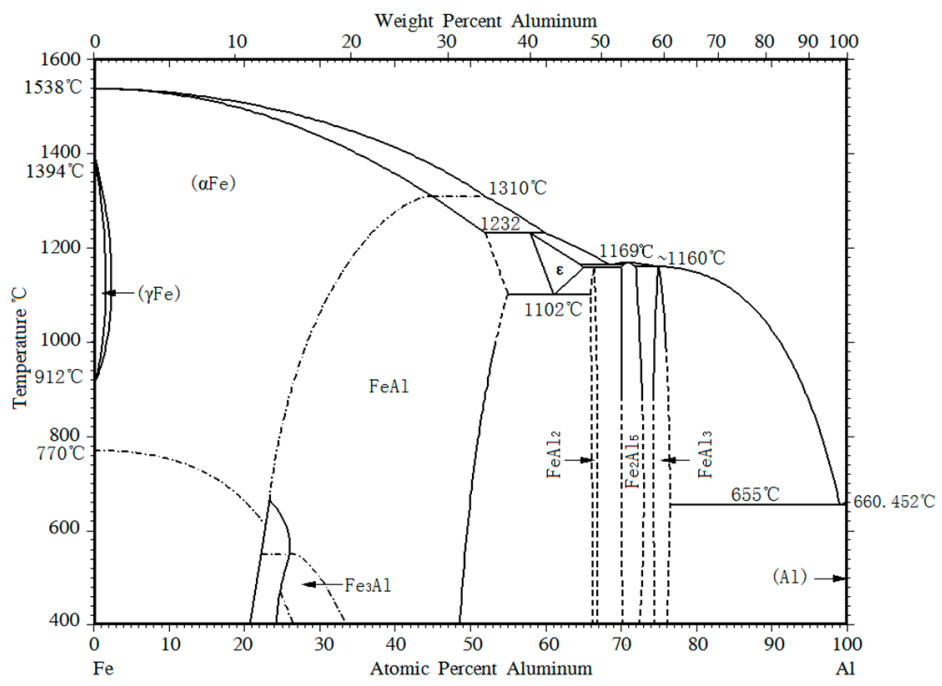

Figure 7. The phase diagram of the Al-Fe binary alloy.

Figure 8 shows the XRD spectrum of the transverse section of keyhole-free FSSW joints. It indicates that the keyhole-free FSSW joints of dissimilar 6082 aluminum alloy and DP600 galvanized steel contained Si-containing solid-solution phase $\alpha(\mathrm{Al})$, Mg-rich phase $\beta\left(\mathrm{Al}_{3} \mathrm{Mg}_{2}\right)$, Fe-rich phase $\theta\left(\mathrm{Al}_{3} \mathrm{Fe}\right)$ and the intermetallic compounds $\mathrm{Mg}_{2} \mathrm{Si}, \mathrm{AlMg}$ and $\mathrm{FeAl}_{2}$. Meanwhile, the uncleaned joints after immersion also contained corrosion products $\mathrm{Fe}_{2} \mathrm{O}_{3}, \mathrm{Fe}_{3} \mathrm{O}_{4}, \mathrm{MgCl}_{2}$ and $\mathrm{AlCl}_{3}$.

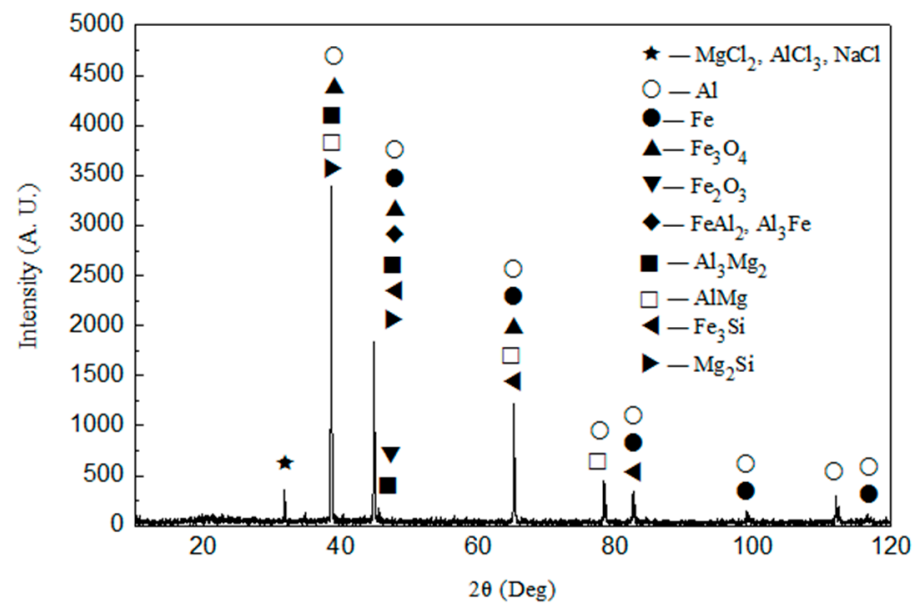

Figure 8. XRD (X-ray Diffraction) spectrum of the transverse section of keyhole-free FSSW joints of dissimilar 6082 aluminum alloy and DP600 galvanized steel.

As shown in Figure 4, the corrosion joint contained two large electrodes, namely, the aluminum matrix anode and the ferrum matrix cathode. The corrosion galvanic couples were formed in $3.5 \%$ $\mathrm{NaCl}$ solution, in which the galvanic current flowed through two electrodes. Meanwhile, the small corrosion galvanic couples were also formed inside the aluminum matrix due to the corrosion potential of different elements not being equal. The electrode potential of the silicon and ferrum elements was higher than that of the surrounding magnesium and aluminum elements. The magnesium and aluminum elements of $\mathrm{Mg}_{2} \mathrm{Si}$ and Si-containing solid-solution phase $\alpha$ (Al) preferentially formed 
anodic dissolution and formed exfoliation corrosion around silicon elements. Fe-rich phase $\theta\left(\mathrm{Al}_{3} \mathrm{Fe}\right)$, as the cathode, caused corrosion of magnesium and formed pitting around $\mathrm{Mg}$-rich phase $\beta\left(\mathrm{Al}_{3} \mathrm{Mg}_{2}\right)$, as the anode. The anodic dissolution reaction is

$$
\mathrm{M} \rightarrow \mathrm{M}^{n+}+n e^{-}
$$

The catholic process is

$$
\mathrm{O}_{2}+2 \mathrm{H}_{2} \mathrm{O}+4 e^{-} \rightarrow 4 \mathrm{OH}^{-}
$$

Figure 9 shows the microscopic corrosion morphology of the transverse section of different zones of 6082 aluminum alloy in keyhole-free FSSW joints before and after immersion for $96 \mathrm{~h}$. Figure $9 \mathrm{~b}$ indicates that the discontinuities of the Fe matrix were mixed in the Al matrix on the WNZ. By comparing Figure $9 b-e$, it can be seen that the amount of pitting was lowest on WNZ. However, HAZ had the most pitting. Furthermore, the extent of pitting on TMAZ was less than that on BM. This indicated that the corrosion resistance of WNZ was significantly better than that of BM and HAZ. The sequence of the corrosion resistance (by decreasing corrosion resistance) was WNZ $>$ TMAZ $>$ BM $>$ HAZ. Figure $9 \mathrm{f}$ shows that serious pitting occurred in the interface of 6082 aluminum alloy, while the surface of steel had no corrosion.

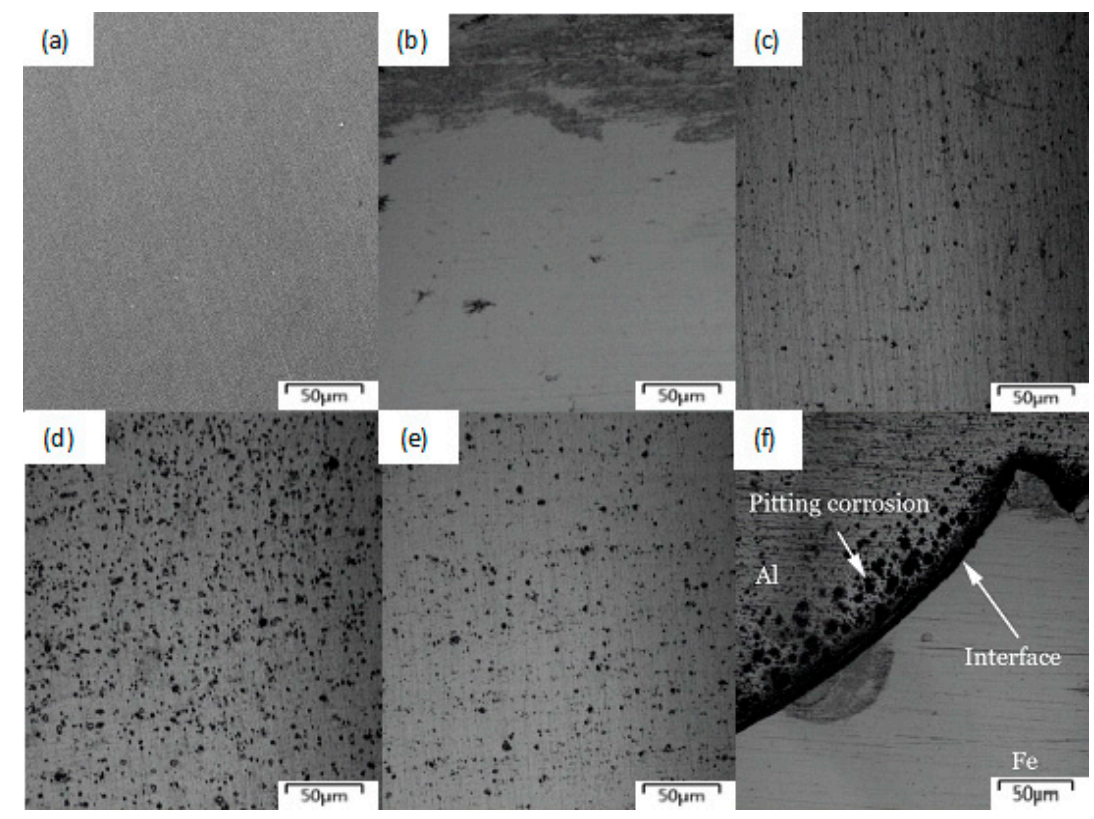

Figure 9. The microscopic corrosion morphology of the transverse section of 6082 aluminum alloy on different zones in keyhole-free FSSW joints before and after immersion for $96 \mathrm{~h}$ : (a) before immersion; (b) WNZ (Weld Nugget Zone); (c) TMAZ (Thermo-mechanically Affected Zone); (d) HAZ (Heat-affected Zone); (e) BM (Base Metal); (f) the interface of aluminum and steel.

\subsection{Electrochemical Analysis}

The corrosion behavior of keyhole-free friction stir spot welding joints of dissimilar 6082 aluminum alloy and DP600 galvanized steel can be characterized by an electrochemical impedance method. Chi660d-c software of Shanghai Chen Hua Instrument Co., Ltd. was used to collect and transform data, and ZSimpWin software was used to analyze electrochemical parameters.

Figure 10 shows the AC impedance spectra of different areas of the transverse section of keyhole-free FSSW joints in $3.5 \% \mathrm{NaCl}$ solution. It was found that the AC impedance spectra of different areas of the welded joints in $3.5 \% \mathrm{NaCl}$ solution has two capacitive arcs besides WNZ in Figure 10. This was because, in the $3.5 \% \mathrm{NaCl}$ solution, fluctuations of oxide film on the surface of 
6082 aluminum alloy took place over three main steps. The first step was that metal ions $\left(\mathrm{Al}^{3+}, \mathrm{Mg}^{2+}\right)$ left the crystal lattice in the passive film and the interface of the metal. This step, however, did not control the entire corrosion process. The second step was a mass-transfer process whereby metal ions migrated from the inside to the outside of the passive film. Finally, the third step occurred at the interface between the corrosive medium and the passive film. In the process, the new compound or passive film were formed by the combination of metal ions and anions adsorbed on the surface of the passive film. At the same time, the new compound and passive film dissolved into the corrosive medium. The passive film became thin and perforated if it is immersed for long enough. Then, the corrosion entered the stable growth stage of the pitting when the third step described above occurred. Meanwhile, the inductive components of the impedance spectrum disappeared, and the impedance was caused by a diffusion process, whereby the reaction products diffused from the solution layer close to the electrode surface to the solution. This time, there was a second capacitance arc. When corrosion time was further increased, the passive film disappeared, which resulted in only one capacitive arc in the impedance spectrum.

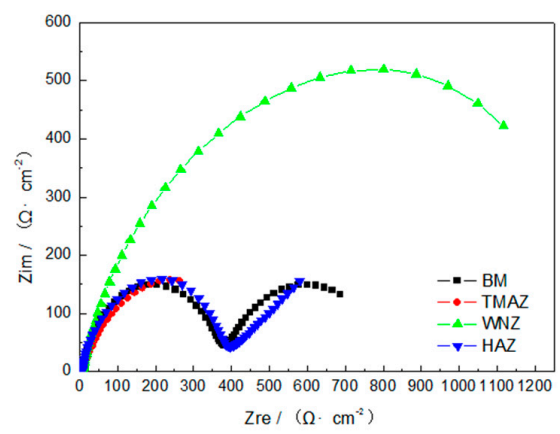

Figure 10. AC impedance spectra of different areas of the transverse section of keyhole-free FSSW joints in $3.5 \% \mathrm{NaCl}$ solution.

Figure 11 shows the equivalent circuit of $R s(Q R p)$. The impedance spectra were fitted using the equivalent circuit of $R s(Q R p)$, where $R s$ is solution resistance, CPE is constant-phase angle element, $Q$ is capacitance of CPE and $R p$ is double-layer charge-transfer resistance. Figure 12 shows the curves of the $R p$ value and the self-corrosion current density, as well as the histogram of the relative corrosion rates of different areas of the transverse section of keyhole-free FSSW joints in $3.5 \% \mathrm{NaCl}$ solution. The red line represents the $R p$ value and the black line represents the self-corrosion current density in Figure 12. The corrosion resistance of different areas of keyhole-free FSSW joints was determined by the $R p$ value. The larger the $R p$ value of the material, the greater its polarization resistance, and the stronger its corrosion resistance. Equally, the smaller its polarization resistance, the higher the corrosion rate in the Nyquist impedance spectrum. WNZ had the largest capacitive arc and the largest $R p$ value as shown in Figures 10 and 12, which indicated that the corrosion resistance of WNZ was the largest and the corrosion rate was the smallest. However, the capacitive arcs of TMAZ, HAZ and BM were much smaller than that of WNZ, and the Rp value of HAZ was the smallest, followed by BM and TMAZ. Therefore, the sequence of the corrosion resistance (by decreasing corrosion resistance) was $\mathrm{WNZ}>\mathrm{TMAZ}>\mathrm{BM}>\mathrm{HAZ}$.

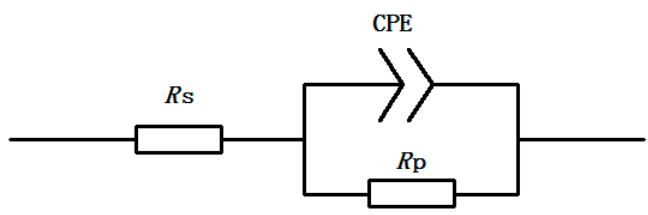

Figure 11. The equivalent circuit of $R \mathrm{~s}(Q R \mathrm{p})$, where $R \mathrm{~s}$ is solution resistance; $R \mathrm{p}$ is polarization resistance; $Q$ is capacitance of CPE (Constant Phase-angle Element). 


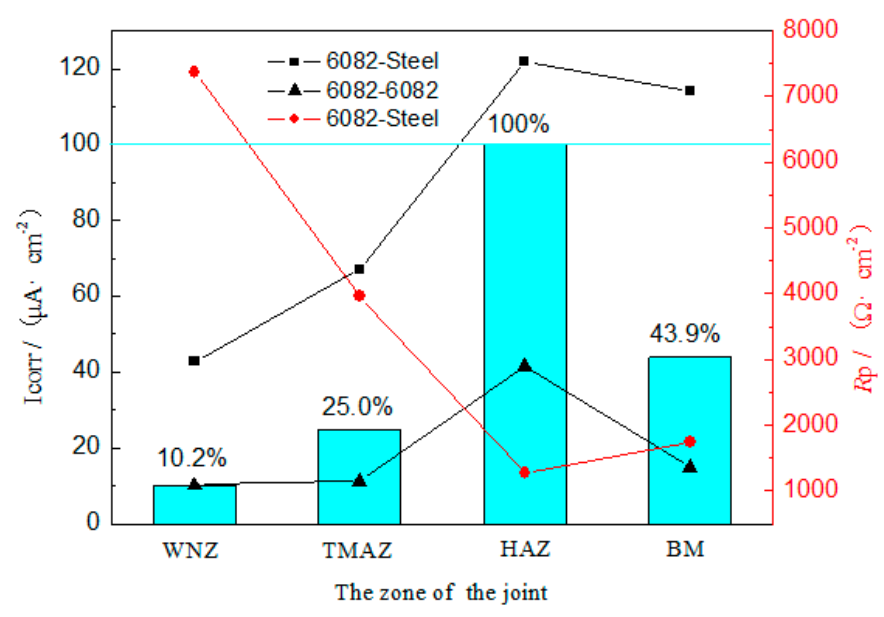

Figure 12. The curves of $R p$ value and self-corrosion current density, and the histogram of the relative corrosion rates of different areas of the transverse section of keyhole-free FSSW joints in 3.5\% $\mathrm{NaCl}$ solution.

Figure 13 shows the polarization curves of different areas of the transverse section of keyhole-free FSSW joints in $3.5 \% \mathrm{NaCl}$ solution. According to the corrosion law of electrode polarization, the self-corrosion potentials were fitted by electrochemical analysis software. Table 2 lists the self-corrosion potentials of different areas of the transverse section of keyhole-free FSSW joints of dissimilar 6082 aluminum alloy and DP600 galvanized steel. The more positive the corrosion potential was, the more stable the corrosion thermodynamics were. The self-corrosion potential of the polarization curve of welded joints had a positive and negative shift of different degrees, as shown in Figure 13 and Table 2. With a gradual positive shift of the corrosion potential, the corrosion tendency gradually slowed down. The corrosion potential of WNZ and HAZ, respectively, reached the maximum and minimum values. Therefore, the corrosion resistance of WNZ was better than that of HAZ.

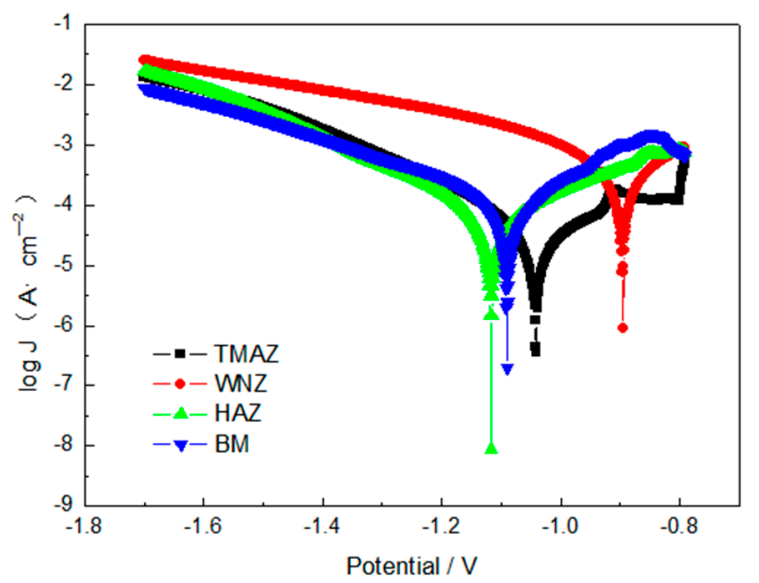

Figure 13. The polarization curves of different areas of the transverse section of keyhole-free FSSW joints in $3.5 \% \mathrm{NaCl}$ solution.

Table 2. The self-corrosion potentials of different areas of the transverse section of keyhole-free FSSW joints.

\begin{tabular}{ccccc}
\hline Zone & WNZ & TMAZ & HAZ & BM \\
\hline Potential/V & -0.895 & -1.041 & -1.117 & -1.090 \\
\hline
\end{tabular}


The greater the corrosion current density, the greater the corrosion rate in kinetics. As shown by the black line in Figure 12, the corrosion current density increased from WNZ to HAZ, which indicated that the corrosion rate increased rapidly near HAZ. Furthermore, the corrosion rate of BM was lower than that of HAZ. The corrosion laws of the keyhole-free FSSW joints of dissimilar 6082 aluminum alloy and DP600 galvanized steel, and similar 6082 aluminum alloy, are the same in Figure 12. By comparing the two curves, it was found that the corrosion rate of similar 6082 aluminum alloy was much lower than that of dissimilar 6082 aluminum alloy and DP600 galvanized steel, especially in vicinity of BM.

The histogram of the relative corrosion rate of different areas in Figure 12 was obtained by counting the amount of pitting in each region represented in Figure 9. As shown from the histogram in Figure 12, the sequence of the corrosion resistance (by decreasing corrosion resistance) was WNZ > TMAZ > BM > HAZ. This conclusion was consistent with the results of the electrochemical analysis.

\section{Conclusions}

The corrosion behavior of keyhole-free friction stir spot welded joints of dissimilar 6082 aluminum alloy and DP600 galvanized steel in 3.5\% NaCl solution has been investigated by the immersion test and electrochemical analysis. The joints of keyhole-free FSSW of dissimilar 6082 aluminum alloy and DP600 galvanized steel have good corrosion resistance in $3.5 \% \mathrm{NaCl}$ solution. Important conclusions are as follows:

1. The corrosion characteristics of dissimilar aluminum/steel keyhole-free FSSW joints are mainly the exfoliation corrosion and pitting on the surface of the aluminum alloy. The fragments of aluminum alloy that were parallel to the metal surface have been separated from the metal body. The pitting seriously occurred on the exfoliation zone. The interfacial layer of the aluminum alloy had a continuous corrosion hole at the junction of aluminum alloy and the interface, but the surface of steel had no corrosion.

2. The impedance of WNZ was the largest, followed by BM and TMAZ. The self-corrosion current density of HAZ was the largest. The sequence of the corrosion resistance of different areas of the transverse section of keyhole-free $\mathrm{FSSW}$ joints in $3.5 \% \mathrm{NaCl}$ solution (by decreasing corrosion resistance) was WNZ > TMAZ > BM > HAZ. Therefore, the joints of keyhole-free FSSW of dissimilar 6082 aluminum alloy and DP600 galvanized steel had better corrosion resistance than base metal in $3.5 \% \mathrm{NaCl}$ solution.

3. The corrosion galvanic couples were formed between elements of silicon and ferrum with a high electrode potential, and magnesium and aluminum with a low electrode potential, around them. Magnesium and aluminum elements of $\mathrm{Mg}_{2} \mathrm{Si}$ and Si-containing solid-solution phase $\alpha$ (Al) preferentially formed anodic dissolution and formed exfoliation corrosion around silicon elements. Fe-rich phase $\theta\left(\mathrm{Al}_{3} \mathrm{Fe}\right)$, as the cathode, caused corrosion of magnesium and formed pitting around the $\mathrm{Mg}$-rich phase $\beta\left(\mathrm{Al}_{3} \mathrm{Mg}_{2}\right)$, as the anode.

Acknowledgments: This work was supported by the national natural science foundation project (No. 10902047) of China and the natural science foundation project (No. 2014GS03264) of Gansu province.

Author Contributions: Zhong-Ke Zhang, Yang Yu and Xi-Jing Wang designed and planned the experiment. Yang Yu and Jian-Fei Zhang made the test.

Conflicts of Interest: The authors declare no conflict of interest.

\section{References}

1. Watanabe, T.; Takayama, H.; Yanagisawa, A. Joining of aluminum alloy to steel by friction stir welding. J. Mater. Proc. Technol. 2006, 178, 342-349. [CrossRef]

2. Chen, Y.C.; Nakata, K. Effect of the surface state of steel on the microstructure and mechanical properties of dissimilar metal lap joints of aluminum and steel by friction stir welding. Metall. Mater. Trans. A 2008, 39, 1985-1992. [CrossRef] 
3. Seifert, H.-P.; Ritter, S.; Leber, H.J.; Roychowdhury, S. Stress corrosion cracking behavior in the transition region of alloy $182 /$ low-alloy reactor pressure vessel steel dissimilar metal weld joints in light water reactor environments. Corrosion 2015, 71, 433-454. [CrossRef]

4. Aval, H.J. Microstructure and residual stress distributions in friction stir welding of dissimilar aluminium alloys. Mater. Des. 2015, 87, 405-413. [CrossRef]

5. Mohammadi, J.; Behnamian, Y.; Mostafaei, A. Friction stir welding joint of dissimilar materials between AZ31B magnesium and 6061 aluminum alloys: Microstructure studies and mechanical characterizations. Mater. Charact. 2015, 101, 189-207. [CrossRef]

6. Gharavi, F.; Matoria, K.A.; Yunusa, R. Corrosion behavior of Al6061 alloy weldment produced by friction stir welding process. J. Mater. Res. Technol. 2015, 4, 314-322. [CrossRef]

7. Wang, Q.; Zhao, Y.; Yan, K. Corrosion behavior of spray formed 7055 aluminum alloy joint welded by underwater friction stir welding. Mater. Des. 2015, 68, 97-103. [CrossRef]

8. Kartsonakis, A.; Dragatogiannis, D.A.; Koumoulos, E.P. Corrosion behavior of dissimilar friction stir welded aluminium alloys reinforced with nanoadditives. Mater. Des. 2016, 102, 56-67. [CrossRef]

9. Sanusi, K.O.; Akinlabi, E.T.; Muzenda, E. Enhancement of corrosion resistance behaviour of frictional stir spot welding of copper. Mater. Today Proc. 2015, 2, 1157-1165. [CrossRef]

10. Akinlabi, E.T.; Andrews, A.; Akinlabi, S.A. Effects of processing parameters on corrosion properties of dissimilar friction stir welds of aluminium and copper. Trans. Nonferrous Met. Soc. China 2014, 24, 1323-1330. [CrossRef]

11. Guo, J.F.; Chen, H.C.; Sun, C.N. Friction stir welding of dissimilar materials between AA6061 and AA7075 Al alloys effects of process parameters. Mater. Des. 2014, 56, 185-192. [CrossRef]

12. Donatus, U.; Thompson, G.E.; Zhou, X. Corrosion susceptibility of dissimilar friction stir welds of AA5083 and AA6082 alloys. Mater. Charact. 2015, 107, 85-97. [CrossRef]

13. Yazdipour, A.; Heidarzadeh, A. Effect of friction stir welding on microstructure and mechanical properties of dissimilar Al 5083-H321 and 316L stainless steel alloy joints. J. Alloys Compd. 2016, 680, 595-603. [CrossRef]

14. Rao, C.V.; Reddy, G.M.; Rao, K.S. Influence of tool pin profile on microstructure and corrosion behavior of AA2219 Al-Cu alloy friction stir weld nuggets. Def. Technol. 2015, 11, 197-208.

15. Yang, Y.; Zhou, L. Improving corrosion resistance of friction stir welding joint of 7075 aluminum alloy by micro-arc oxidation. J. Mater. Sci. Technol. 2014, 30, 1251-1254. [CrossRef]

16. Aval, H.J. Influences of pin profile on the mechanical and microstructural behaviors in dissimilar friction stir welded AA6082-AA7075 butt Joint. Mater. Des. 2015, 67, 413-421. [CrossRef]

17. Khodabakhshi, F.; Simchi, A.; Kokabi, A.H. Similar and dissimilar friction-stir welding of an PM aluminum-matrix hybrid nanocomposite and commercial pure aluminum: Microstructure and mechanical properties. Mater. Sci. Eng. A 2016, 666, 225-237. [CrossRef]

18. Hariri, M.B.; Shiri, S.G.; Yaghoubinezhad, Y.; Rahvard, M.M. The optimum combination of tool rotation rate and traveling speed for obtaining the preferable corrosion behavior and mechanical properties of friction stir welded AA5052 aluminum alloy. Mater. Des. 2013, 50, 620-634. [CrossRef]

19. Srinivasan, P.B.; Arora, K.S.; Dietzel, W. Characterisation of microstructure, mechanical properties and corrosion behaviour of an AA2219 friction stir weldment. J. Alloys Compd. 2010, 492, 631-637. [CrossRef]

20. Paglia, C.S.; Buchheit, R.G. Microstructure, microchemistry and environmental cracking susceptibility of friction stir welded 2219-T87. Mater. Sci. Eng. A 2006, 429, 107-114. [CrossRef]

21. Emilie, B.; Angeline, P.Q.; Monique, P. Relationship between microstructure, microhardness and corrosion sensitivity of an AA2024-T3 friction stir welded joint. Corros. Sci. 2011, 53, 3026-3034.

22. Fonda, R.W.; Pao, P.S.; Jones, H.N. Microstructure, mechanical properties, and corrosion of friction stir welded Al 5456. Mater. Sci. Eng. 2009, 519, 1-8. [CrossRef]

23. Shen, C.B.; Zhang, J.Y.; Ge, J.P. Microstructures and electrochemical behaviors of the friction stir welding dissimilar weld. J. Environ. Sci. 2011, 23, S32-S35. [CrossRef]

24. Shen, C.B.; Wang, Z.Z.; Quan, G.F. Microstructures and electrochemical performance of welds of 6082 aluminum alloy prepared by friction stir welding. Corros. Sci. Prot. Technol. 2010, 22, 400-402.

25. Shen, C.B.; Zhao, Y.D.; Liu, S.H. Electrochemical corrosion behavior of friction stir welding dissimilar weld of 5083 and 6082 aluminum alloy. J. Aeronaut. Mater. 2009, 29, 24-28.

26. Kang, J.; Liang, S.Y.; Li, G. Effect of processing parameters on microstructure and corrosion behavior of friction stir welded 2024 aluminum alloy. Corros. Sci. Prot. Technol. 2012, 24, 51-56. 
27. Wadeson, D.A.; Zhou, X.; Thompson, G.E.; Skeldon, P.; Djapic Oosterkamp, L.; Scamans, G. Corrosion behavior of friction stir welded AA7108 T79 aluminum alloy. Corros. Sci. 2006, 48, 887-897. [CrossRef]

28. Xu, W.F.; Liu, J.H.; Zhu, H.Q. Pitting corrosion of friction stir welded aluminum alloy thick plate in alkaline chloride solution. Electrochim. Acta 2010, 55, 2918-2923. [CrossRef]

29. Surekha, K.; Murty, B.S.; Prasad, R.K. Microstructural characterization and corrosion behavior of multipass friction stir processed AA2219 aluminium alloy. Surf. Coat. Technol. 2008, 202, 4057-4068. [CrossRef]

30. Surekha, K.; Murty, B.S.; Prasad, R.K. Effect of processing parameters on the corrosion behaviour of friction stir processed AA 2219 aluminum alloy. Solid State Sci. 2009, 11, 907-917. [CrossRef]

31. Surekha, K.; Murty, B.S.; Prasad, R.K. Comparison of corrosion behavior of friction stir processed and laser melted AA 2219 aluminium alloy. Mater. Des. 2011, 32, 4502-4508. [CrossRef]

32. Hsieh, M.-J.; Lee, R.-T.; Chiou, Y.-C. Friction stir spot fusion welding of low-carbon steel to aluminum alloy. J. Mater. Proc. Technol. 2017, 240, 118-125. [CrossRef]

33. Dong, H.; Chena, S.; Song, Y.; Guo, X.; Zhang, X.; Sun, Z. Refilled friction stir spot welding of aluminum alloy to galvanized steel sheets. Mater. Des. 2016, 94, 457-466. [CrossRef]

34. Cho, H.H.; Kang, S.H.; Kim, S.H.; Oh, K.H.; Kim, H.J.; Chang, W.-S.; Han, H.N. Microstructural evolution in friction stir welding of high-strength linepipe steel. Mater. Des. 2012, 34, 258-267. [CrossRef]

35. Wang, X.; Wang, J.; Yue, X.; Gao, Y. Effect of aging treatment on the exfoliation corrosion and stress corrosion cracking behaviors of 2195 Al-Li alloy. Mater. Des. 2015, 67, 596-605. [CrossRef]

36. Navaser, M.; Atapour, M. Effect of friction stir processing on pitting corrosion and intergranular attack of 7075 aluminum alloy. J. Mater. Sci. Technol. 2017, 33, 155-165. [CrossRef]

(C) 2017 by the authors. Licensee MDPI, Basel, Switzerland. This article is an open access article distributed under the terms and conditions of the Creative Commons Attribution (CC BY) license (http://creativecommons.org/licenses/by/4.0/). 